\title{
Adapting Entities across Languages and Cultures
}

\author{
Denis Peskov \\ Computer Science \\ University of Maryland \\ dpeskoveumd.edu
}

Jordan Boyd-Graber

CS, LSC, UMIACS, and iSchool

University of Maryland

j.gg@umiacs . umd.edu

\begin{abstract}
How would you explain Bill Gates to a German? He is associated with founding a company in the United States, so perhaps the German founder Carl Benz could stand in for Gates in those contexts. This type of translation is called adaptation in the translation community (Vinay and Darbelnet, 1995). Until now, this task has not been done computationally. Automatic adaptation could be used in natural language processing for machine translation and indirectly for generating new question answering datasets and education. We propose two automatic methods and compare them to human results for this novel NLP task. First, a structured knowledge base adapts named entities using their shared properties. Second, vector arithmetic and orthogonal embedding mappings identify better candidates, but at the expense of interpretable features. We evaluate our methods through a new dataset $^{1}$ of human adaptations.
\end{abstract}

\section{When Translation Misses the Mark}

Imagine reading a translation from German, "I saw Merkel eating a Berliner from Dietsch on the ICE". This sentence is opaque without cultural context.

An extreme cultural adaptation for an American audience could render the sentence as "I saw Biden eating a Boston Cream from Dunkin' Donuts on the Acela", elucidating that Merkel is in a similar political post to Biden; that Dietsch (like Dunkin' Donuts) is a mid-range purveyor of baked goods; both Berliners and Boston Creams are filled, sweet pastries named after a city; and ICE and Acela are slightly ritzier high-speed trains. Human translators make this adaptation when it is appropriate to the translation (Gengshen, 2003).

\footnotetext{
${ }^{1}$ Available at https://go.umd.edu/adaptation
}

\author{
Viktor Hangya \\ Center for Information and Language Processing \\ LMU Munich \\ hangyavecis.lmu.de
}

Bill Gates

\begin{tabular}{lll}
\hline Top Adaptations: & & \\
WikiData & 3CosAdd & Human \\
F. Zeppelin & congstar & A. Bechtolsheim \\
Günther Jauch & Alnatura & Dietmar Hopp \\
N. Harnoncourt & GMX & Carl Benz \\
\hline
\end{tabular}

Table 1: WikiData and unsupervised embeddings (3CosAdd) generate adaptations of an entity, such as Bill Gates. Human adaptations are gathered for evaluation. American and German entities are color coded.

Because adaptation is understudied, we leave the full translation task to future work. Instead, we focus on the task of cultural adaptation of entities: given an entity in a source, what is the corresponding entity in English? Most Americans would not recognize Christian Drosten, but the most efficient explanation to an American would be to say that he is the "German Anthony Fauci" (Loh, 2020). We provide top adaptations suggested by algorithms and humans for another American involved with the pandemic response, Bill Gates, in Table 1.

Can machines reliably find these analogs with minimal supervision? We generate these adaptations with structured knowledge bases (Section 3) and word embeddings (Section 4). We elicit human adaptations (Section 5) to evaluate whether our automatic adaptations are plausible (Section 5.3).

\section{Wer ist Bill Gates?}

We define cultural adaptation and motivate its application for tasks like creating culturally-centered training data for QA. Vinay and Darbelnet (1995) define adaptation as translation in which the relationship not the literal meaning between the receiver and the content needs to be recreated.

You could formulate our task as a tradi- 
tional analogy Drosten::Germany as Fauci::United States (Turney, 2008; Gladkova et al., 2016), but despite this superficial resemblance (explored in Section 4), traditional approaches to analogy ignore the influence of culture and are typically within a language. Hence, analogies are tightly bound with culture; humans struggle with analogies outside their culture (Freedle, 2003).

We can use this task to identify named entities (Kasai et al., 2019; Arora et al., 2019; Jain et al., 2019) and for understanding other cultures (Katan and Taibi, 2004).

\section{1 ... and why Bill Gates?}

This task requires a list of named entities adaptable to other cultures. Our entities come from two sources: a subset of the top 500 most visited German/English Wikipedia pages and the nonofficial characterization list (Veale, 2016, NOC), "a source of stereotypical knowledge regarding popular culture, famous people (real and fictional) and their trade-mark qualities, behaviours and settings". Wikipedia contains a plethora of singers and actors; we filter the top 500 pages to avoid a pop culture skew. ${ }^{2}$ We additionally select all Germans and a subset of Americans from the Veale NOC list as it is human-curated, verified, and contains a broader historical period than popular Wikipedia pages. Like other semantic relationships (Boyd-Graber et al., 2006), this is not symmetric. Thus, we adapt entities in both directions; while Berlin is the German Washington, DC, there is less consensus on what is the American Berlin, as Berlin is both the capital, a tech hub, and a film hub. A full list of our entities is provided in Appendix D.

\section{Adaptation from a Knowledge Base}

We first adapt entities with a knowledge base. We use WikiData (Vrandečić and Krötzsch, 2014), a structured, human-annotated representation of Wikipedia entities that is actively developed. This resource is well-suited to the task as features are standardized both within and across languages.

Many knowledge bases explicitly encode the nationality of individuals, places, and creative works. Entities in the knowledge base are a discrete sparse vector, where most dimensions are unknown or not applicable (e.g., a building does not have a spouse).

\footnotetext{
${ }^{2}$ We discuss the applicability of using Wikipedia (i.e., what proportion of the English Wikipedia is visited from the United States) in Appendix B.
}

For example, Angela Merkel is a human (instance of), German (country of citizenship), politician (occupation), Rotarian (member of), Lutheran (religion), 1.65 meters tall (height), and has a $\mathrm{PhD}$ (academic degree). How would we find the "most similar" American adaptation to Angela Merkel? Intuitively, we should find someone whose nationality is American.

Some issues immediately present themselves; contemporary entities will have more non-zero entries than older entities. Some characteristics are more important than others: matching unique attributes like "worked as journalist" is more important than matching "is human".

Each entity in WikiData has "properties", which we can think about as the dimension of a sparse vector and "values" that those properties can take on. For example, Merkel has the properties "occupation" and "academic degree". Values for those properties are that her "occupation" is "politician" and her "academic degree" is a "doctorate". To match entities across cultures, we focus on matching properties rather than values; many of the values are more relevant inside a culture. For example, we cannot find American politicians who belong to the Christian Democratic Union, but we can find politicians who have an academic degree and a dissertation title.

As a toy example, if Beethoven, Merkel, and Bach all have only two properties: Beethoven has an "occupation" and "genre", Merkel has an "Erdôs number" and "political party", and Bach has a "occupation" and "genre", then Beethoven and Bach has a distance of zero and are the closest entities while Merkel has a distance of two since \{ "Erdős number", "political party"] is two away from ["occupation", "genre"\}.

First, we bifurcate WikiData into two sets: an American set $\mathcal{A}$ for items which contain the value "United States of America" and a German set $\mathcal{D}$ for those with German values. ${ }^{3}$ This is a liberal approximation, but it successfully excludes roughly seven out of the eight million items in WikiData. Then we explore the properties from WikiData. We create entity vectors with dimensions corresponding to frequently-occurring properties.

\footnotetext{
${ }^{3}$ While the geopolitical definition of American is straightforward, the German nation state is more nuanced (Schulze, 1991). Following Green (2003), we adopt members of the Zollverein or the German Confederation as "German" as well as their predecessor and successor states. This approach is a more inclusive (Großdeutschland) definition of "German" culture.
} 
The properties are discrete and categorical; Merkel either has an "occupation" or she does not. Each entity then has a sparse vector. We calculate the similarity of the vectors with Faiss's $L_{2}$ distance (Johnson et al., 2021) and for each vector in $\mathcal{A}$ find the closest vector in $\mathcal{D}$ and vice versa.

So who is the American Angela Merkel? One possible answer is Woodrow Wilson, a member of a "political party", who had a "doctoral advisor" and a "religion", and ended up with "awards". This answer may be unsatisfying as it was Barack Obama who sat across from Merkel for nearly a decade. To capture these more nuanced similarities, we turn to large text corpora in Section 4.

\section{An Alternate Embedding Approach}

While the classic NLP vector example (Mikolov et al., 2013c) isn't as magical as initially claimed (Rogers et al., 2017), it provides useful intuition. We can use the intuitions of the cliché:

$$
\overrightarrow{\text { King }}-\overrightarrow{\text { Man }}+\overrightarrow{\text { Woman }}=\overrightarrow{\text { Queen }}
$$

to adapt between languages.

This, however, requires relevant embeddings. First, we use the entire Wikipedia in English and German, preprocessed using Moses (Koehn et al., 2007). We follow Mikolov et al. (2013b) and use named entity recognition (Honnibal et al., 2020) to tokenize entities such as Barack_Obama.

We use word2vec (Mikolov et al., 2013b), rather than FastText (Bojanowski et al., 2017), as we do not want orthography to influence the similarity of entities. Angela Merkel in English and in German have quite different neighbors, and we intend to keep it that way by preserving the distinction between languages.

However, the standard word2vec model assumes a single monolingual embedding space. We use unsupervised Vecmap (Artetxe et al., 2018), a leading tool for creating cross-lingual word embeddings, to build bilingual word embeddings. We propose two approaches for adaptation.

3CosAdd We follow the word analogy approach of $3 \mathrm{CosAdd}^{4}$ (Levy and Goldberg, 2014; Köper et al., 2016). American $\rightarrow$ German adaptation takes the source entity's $(v)$ embedding in the English vector space and looks for its adaptation $\left(u^{*}\right)$ based on embeddings in the German space. This is like the word analogy task, i.e., what entity has the

\footnotetext{
${ }^{4}$ We experiment with 3 CosMul as well but found 3 CosAdd generally more robust.
}

role in the German culture as $v$ does in American culture. As an example, Merkel has a similar role in the German culture as Biden. Formally, the adaptation of the English entity $v$ into German is

$$
\begin{aligned}
& \vec{a} \equiv \operatorname{avg}\left({\overrightarrow{E^{e n}}}_{\text {United_States }}, \overrightarrow{E^{d e}} \text { USA }\right) \\
& \vec{d} \equiv \operatorname{avg}\left({\overrightarrow{E^{e n}}}_{\text {Germany }}, \overrightarrow{E^{d e}} \text { Deutschland }\right) \\
& u^{*}=\underset{u \in V^{d e}}{\arg \max } \operatorname{sim}\left(\overrightarrow{E_{u}^{d e}}, \overrightarrow{E_{v}^{e n}}-\vec{a}+\vec{d}\right),
\end{aligned}
$$

where $\overrightarrow{E_{w}^{l}}$ is the embedding of word $w$ in language $l, V^{\text {de }}$ is the German vocabulary and sim is the cosine similarity. The American anchor word $\vec{a}$ and German anchor $\vec{d}$ represent the American and German cultures. ${ }^{5}$ We average the English and German embeddings of the individual word types for robust anchor vectors. In standard analogies, as in Equation 1, the $\vec{d}$ and $\vec{d}$ vectors are different for each test pair; here they are the same for each example, as we always are pivoting between the two cultures.

Learned adaptation To eliminate the need for manual anchor selection for both cultures, our second approach learns the adaptation as a linear transformation of source embeddings to the target culture given a few adaptation examples. Specifically, we use the human adaptations sourced for the Wikipedia entities as training for the Veale NOC ones. We follow the work of Mikolov et al. (2013a) and learn a transformation matrix $\mathbf{W}_{e n \rightarrow d e}$ for American $\rightarrow$ German by minimizing the $L_{2}$ distance of $\mathbf{W}_{e n \rightarrow d e} \vec{E}_{v_{i}}^{e n}$ and $\vec{E}_{u_{i}}^{d e}$ over gold adaptation $v_{i}, u_{i=1}^{n}$ entity pairs. The adaptation of a source entity $v$ is $u^{*}=\mathbf{W}_{e n \rightarrow d e} \vec{E}_{v}^{e n}$. Likewise, we learn the reverse mapping $\mathbf{W}_{d e \rightarrow e n}$ for German $\rightarrow$ American adaptation. This requires supervised training data-but not much (Conneau et al., 2018)—which we collect in Section 5.

\section{Comparing Automation to Human Judgment}

The automated methods can generate entities at scale, but humans have to evaluate their relevance.

\subsection{Adaptation by Locals}

Since quality control is difficult for generation (Peskov et al., 2019), we need users who

\footnotetext{
${ }^{5}$ USA is used to refer to the United States in German. Der Spiegel, the largest newspaper, calls their US section USA.
} 
will answer the task accurately. We recruit five American citizens educated at American universities and five German citizens educated at German ones. These human annotations serve as a gold standard against which we can compare our automated approaches. To improve the user experience, we create an interface that provides a brief summary of each source entity from Wikipedia and asks the users to select a target adaptation that autocompletes Wikipedia page titles (all entities; targets are not limited to the lists in Section 2) in a text box $a$ la answer selection in Wallace et al. (2019). The annotation task requires two hours for our users to complete. Obviously, German annotators are more familiar with German culture than the Americans, and vice-versa. Annotators translate into their native language. Since we are focusing on popular entities, they are often known despite the cultural divide, but the introductory paragraph from Wikipedia reminds users if not.

\subsection{Are the Adaptations Plausible?}

To validate and compare all our adaptation strategies' precision, five German translators ${ }^{6}$ who understand American culture assess the adaptations. The top five adaptations from WikiData, 3CosAdd, learned adaptation, and humans - as well as five randomly selected options from the human poolare evaluated for plausibility on a five-level Likert scale. ${ }^{7}$ Fleiss' Kappa (0.382) and Krippendorf's Alpha (0.381) assess interannotator Agreement; this "fair" agreement suggests that vetting an adaptation is challenging and sometimes subjective, even for translators.

\subsection{Why Adaptation is Difficult}

Embedding adaptations are better than Wikidata's, and human adaptations are better still (Figure 1). Thus, we use human adaptations as the gold standard for evaluating recall. Only the learned embedding method uses training data, so we use human adaptations from Wikipedia to train the projection matrix and evaluate (for all methods) using human adaptations the NOC list. Given that the task is subjective, we take our results with a grain of salt given cultural variation (e.g., some people view Angela Merkel's conservatism as a defining characteristic, while others focus on her science pedigree).

\footnotetext{
${ }^{6}$ Recruited through Upwork for $\$ 40$ each.

${ }^{7}$ Our custom Qualtrics survey is provided in Appendix C. The order of adaptations is randomized and assessed on a Likert scale with anchors from Jurgens et al. (2014).
}

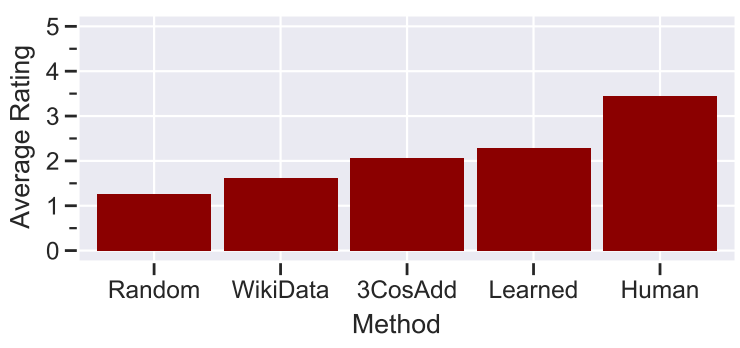

Figure 1: We validate adaptation strategies with expert translators on a five-point Likert scale. The human-generated adaptations are rated best-between "related" (3) and "similar" (4). These human adaptations become the reference for evaluation in Table 2 .

\begin{tabular}{lllll}
\hline Data & Metric & WikiData 3CosAdd & Learned \\
\hline American $\rightarrow$ German & & & \\
& & & & \\
& Rec@5 & $7.5 \%$ & $\mathbf{1 4 . 2 \%}$ & - \\
Wikipedia & Rec@ 100 & $34.4 \%$ & $\mathbf{5 2 . 8 \%}$ & - \\
& MRR & 0.05 & $\mathbf{0 . 1 0}$ & - \\
\hline \multirow{5}{*}{ Veale NOC } & Rec@5 & $3.0 \%$ & $22.9 \%$ & $\mathbf{2 8 . 6 \%}$ \\
& Rec@100 & $42.4 \%$ & $\mathbf{5 1 . 4 \%}$ & $45.7 \%$ \\
& MRR & 0.03 & 0.17 & $\mathbf{0 . 2 4}$ \\
\hline German $\rightarrow$ American & & & \\
& & & & \\
Wikipedia & Rec@5 & $3.1 \%$ & $\mathbf{1 7 . 2 \%}$ & - \\
& Rec@ 100 & $15.4 \%$ & $\mathbf{4 0 . 5 \%}$ & - \\
& MRR & 0.01 & $\mathbf{0 . 1 2}$ & - \\
\hline \multirow{5}{*}{ Veale NOC } & Rec@5 & $0.0 \%$ & $\mathbf{2 5 . 0 \%}$ & $\mathbf{2 5 . 0 \%}$ \\
& Rec@ 100 & $25.0 \%$ & $\mathbf{7 0 . 0 \%}$ & $55.0 \%$ \\
& MRR & 0.02 & 0.12 & $\mathbf{0 . 1 5}$ \\
\hline
\end{tabular}

Table 2: If we consider human adaptations as correct, where do they land in the ranking of automatic adaptation candidates? In this recall-oriented approach, learned mappings (which use a small number of training pairs), rate highest.

We use the mean reciprocal rank (Voorhees, 1999, MRR) to measure how high the gold adaptations are ranked by our other adaptation strategies. Since MRR decreases geometrically and our gold standard is not exhaustive, the Recall@5, and @ 100 metrics are more intuitive. We calculate Recall@n by measuring what fraction of the correct adaptations of a source entity is retrieved in the top $n$ predictions. ${ }^{8}$ Table 2 validates that the human annotations are near the top of the automatic adaptations; the precision-oriented evaluation (Figure 1) validates whether the top of the list is reasonable. All human annotations and a sample of the automatic adaptations are provided in Appendix D.

\footnotetext{
${ }^{8}$ This is often referred to as P@ $n$ in bilingual lexicon induction literature (Conneau et al., 2018).
} 


\subsection{Qualitative Analysis}

There is no single answer to what makes a good adaptation. Let us return to the question of who Bill Gates is, which underlines how there is often no one right answer to this question but several context-specific possibilities. The human adaptations show the range of plausible adaptations, each appropriate for a particular facet of the position Bill Gates has in US society. As previously mentioned, Carl Benz represents a larger than life founder who created an entire industry with his company. However, Carl Benz made cars, not computers.

Even within technology, different adaptations highlight different aspects of Bill Gates. Like the implementer of the BASIC programming language, Konrad Zuse contributed to computers that were more than single-purpose machines. Just as as Bill Gates's Microsoft is seen as a stodgy tech giant, Dietmar Hopp founded SAS, a giant German tech company that is more often discussed in board rooms than in living rooms. And because the epicenter of modern tech is America's West Coast, Andreas von Bechtolsheim represents a German founder of Sun Microsystems and early Google investor that made his way to Silicon Valley.

Other times, there is more consensus: a majority of raters declare Angela Merkel is the German Hilary Clinton, and Joseph Smith is the American Martin Luther. There are even some unanimous adaptations: Bavaria is the German California. Adaptations of fictional characters seem particularly difficult, although this may represent the supremacy of American popular culture; Superman and Homer Simpson are so well known in Germany that there are no clear adaptations; Till Eulenspiegel, Maverick, Bibi Blocksberg are not superheroes from a dying world and Heidi is not a dumb, bald everyman.

\section{A New Computational Task}

We formally introduce entity adaptation as a new computational task. Word2vec embeddings and WikiData can be used to figuratively - not just literally - translate entities into a different culture. Humans are better at generating candidates for this task than our computational methods (Figure 1). These methods are well-motivated, but have room for improvement. Knowledge bases improve over time and increased coverage of entities-as well as improved information about each entity-would improve the method. Alternate word embedding approaches - perhaps those that discard orthography-may provide better candidates. Even humans occasionally disagree with other humans on this task, so evaluation for this task is nontrivial.

Our new dataset of machine-generated adaptations, human adaptations, and human evaluation of these adaptations can serve as an evaluation for future automatic methods.

People need NLP systems that reflect their language and culture, but datasets are lacking: adaptation can help. There has been an explosion of English-language QA datasets, but other languages continue to lag behind. Several approaches try to transfer English's bounty to other languages (Lewis et al., 2020; Artetxe et al., 2019), but most of the entities asked about in major QA datasets are American (Gor et al., 2021). Adapting entire questions will require not just adapting entities and non-entities in tandem but will also require integration with machine translation (Kim et al., 2019; Hangya and Fraser, 2019). Our automatic methods did not create precise adaptations, but the alternative "incorrect" adaptations may be useful for low-precision tasks, such as generating numerous simple open-ended questions or gauging the popularity of a entity.

Given the existence of robust datasets in high resource languages can we adapt, rather than literally translate, them to other cultures and languages?

\section{Acknowledgments}

Peskov was supported by a DAAD Research Fellowship and by the wonderful faculty and students of Ludwig Maximilians Universität München. Fraser is supported by the European Research Council (ERC) under the European Union's Horizon 2020 research and innovation programme (grant agreement No. 640550) and by German Research Foundation (DFG; grant FR 2829/4-1). Boyd-Graber is supported by NSF Grant IIS-1822494. Any opinions, findings, conclusions, or recommendations expressed here are those of the authors and do not necessarily reflect the view of the sponsors.

We thank Sander Schulhoff for his web development expertise and Pedro Rodriguez for his help with processing WikiData. Thanks to Phillip Dufter, Benno Krojer, Stephan Huber, Janika Linke, Andrew Guo, Adam Visokay, Christian Rice, Connor Knight, and others for help with adaptations. 


\section{Ethics}

We worked with human participants to collect our data. They are all adults who participated of their own volition and no payment was made. No personal data was collected or used for the dataset. For evaluation of the adaptations, we hired translators through Upwork. They were paid $\$ 40$ for a task that took roughly between one and two hours.

The broad motivation of this work is to spread cultural understanding. Humans must be kept inthe-loop for making claims about cultural relevance. Having multiple diverse opinions is necessary for supporting any cultural claim. Like with language, nationality is often correlated with culture, but is not synonymous. Large countries contain multitudes, while some nationalities (e.g., Kurds) lack a de jure nation but span many nations. We elide this detail and focus on information often available in knowledge bases.

These lists contain figures that are controversial. From a research perspective, research datasets should reflect the real world and prior work, thus we include prominent entities as identified by Veale NOC and Wikipedia. Any list may contain biases in the collection processes, and this should not be thought of as an exclusive and definitive list, but as a start that can be refined and ultimately expanded to other cultures.

\section{References}

Ravneet Arora, Chen-Tse Tsai, Ketevan Tsereteli, Prabhanjan Kambadur, and Yi Yang. 2019. A semiMarkov structured support vector machine model for high-precision named entity recognition. In Proceedings of the Association for Computational Linguistics.

Mikel Artetxe, Gorka Labaka, and Eneko Agirre. 2018. A robust self-learning method for fully unsupervised cross-lingual mappings of word embeddings. In Proceedings of the Association for Computational Linguistics.

Mikel Artetxe, Sebastian Ruder, and Dani Yogatama. 2019. On the cross-lingual transferability of monolingual representations. CoRR, abs/1910.11856.

Piotr Bojanowski, Edouard Grave, Armand Joulin, and Tomas Mikolov. 2017. Enriching word vectors with subword information. In Proceedings of the Association for Computational Linguistics.

Jordan Boyd-Graber, Christiane Fellbaum, Daniel Osherson, and Robert Schapire. 2006. Adding dense, weighted, connections to WordNet. In Proc. Global
WordNet Conference 2006. Global WordNet Association.

Alexis Conneau, Guillaume Lample, Marc'Aurelio Ranzato, Ludovic Denoyer, and Hervé Jégou. 2018. Word translation without parallel data. In Proceedings of the International Conference on Learning Representations.

Roy Freedle. 2003. Correcting the SAT's ethnic and social-class bias: A method for reestimating sat scores. Harvard Educational Review, 73(1):1-43.

$\mathrm{Hu}$ Gengshen. 2003. Translation as adaptation and selection. Perspectives: Studies in Translatology, 11(4):283-291.

Anna Gladkova, Aleksandr Drozd, and Satoshi Matsuoka. 2016. Analogy-based detection of morphological and semantic relations with word embeddings: what works and what doesn't. In Proceedings of the NAACL Student Research Workshop.

Maharshi Gor, Kellie Webster, and Jordan BoydGraber. 2021. Toward deconfounding the influence of subject's demographic characteristics in question answering. In Proceedings of Empirical Methods in Natural Language Processing.

Abigail Green. 2003. Representing Germany? the zollverein at the world exhibitions, 1851-1862. The Journal of Modern History, 75(4):836-863.

Viktor Hangya and Alexander Fraser. 2019. Unsupervised parallel sentence extraction with parallel segment detection helps machine translation. In Proceedings of the Association for Computational Linguistics.

Matthew Honnibal, Ines Montani, Sofie Van Landeghem, and Adriane Boyd. 2020. spaCy: Industrial-strength Natural Language Processing in Python.

Alankar Jain, Bhargavi Paranjape, and Zachary C. Lipton. 2019. Entity projection via machine translation for cross-lingual NER. In Proceedings of the Association for Computational Linguistics.

Jeff Johnson, Matthijs Douze, and Hervé Jégou. 2021. Billion-scale similarity search with gpus. IEEE Transactions on Big Data, 7(3):535-547.

David Jurgens, Mohammad Taher Pilehvar, and Roberto Navigli. 2014. SemEval-2014 Task 3: Cross-level semantic similarity. In Proceedings of the Workshop on Semantic Evaluation. Association for Computational Linguistics.

Jungo Kasai, Kun Qian, Sairam Gurajada, Yunyao Li, and Lucian Popa. 2019. Low-resource deep entity resolution with transfer and active learning. In Proceedings of the Association for Computational Linguistics. 
David Katan and Mustapha Taibi. 2004. Translating cultures: An introduction for translators, interpreters and mediators. Routledge.

Yunsu Kim, Yingbo Gao, and Hermann Ney. 2019 Effective cross-lingual transfer of neural machine translation models without shared vocabularies. In Proceedings of the Association for Computational Linguistics.

Philipp Koehn, Hieu Hoang, Alexandra Birch, Chris Callison-Burch, Marcello Federico, Nicola Bertoldi, Brooke Cowan, Wade Shen, Christine Moran, Richard Zens, et al. 2007. Moses: Open source toolkit for statistical machine translation. In Proceedings of the Association for Computational Linguistics.

Maximilian Köper, Sabine Schulte im Walde, Max Kisselew, and Sebastian Padó. 2016. Improving zero-shot-learning for german particle verbs by using training-space restrictions and local scaling. In Proceedings of the Fifth Joint Conference on Lexical and Computational Semantics.

Omer Levy and Yoav Goldberg. 2014. Linguistic regularities in sparse and explicit word representations. In Conference on Computational Natural Language Learning.

Patrick Lewis, Barlas Oğuz, Ruty Rinott, Sebastian Riedel, and Holger Schwenk. 2020. MLQA: Evaluating cross-lingual extractive question answering. In Proceedings of the Association for Computational Linguistics.

Tim Loh. 2020. Germany has its own Dr. Fauci-and actually follows his advice. Bloomberg.

Tomas Mikolov, Quoc V. Le, and Ilya Sutskever. 2013a Exploiting Similarities among Languages for Machine Translation. CoRR, abs/1309.4.

Tomas Mikolov, Ilya Sutskever, Kai Chen, Greg S Corrado, and Jeff Dean. 2013b. Distributed representations of words and phrases and their compositionality. In Proceedings of Advances in Neural Information Processing Systems.

Tomáš Mikolov, Wen-tau Yih, and Geoffrey Zweig. 2013c. Linguistic regularities in continuous space word representations. In Conference of the North American Chapter of the Association for Computational Linguistics.

Denis Peskov, Nancy Clarke, Jason Krone, Brigi Fodor, Yi Zhang, Adel Youssef, and Mona Diab. 2019. Multi-domain goal-oriented dialogues (MultiDoGO): Strategies toward curating and annotating large scale dialogue data. In Proceedings of Empirical Methods in Natural Language Processing.

Anna Rogers, Aleksandr Drozd, and Bofang Li. 2017. The (too many) problems of analogical reasoning with word vectors. In Proceedings of the Joint Conference on Lexical and Computational Semantics.
Hagen Schulze. 1991. The Course of German Nationalism: From Frederick the Great to Bismarck 1763-1867. Cambridge University Press.

Peter D Turney. 2008. A uniform approach to analogies, synonyms, antonyms, and associations. In Proceedings of International Conference on Computational Linguistics.

Tony Veale. 2016. Round up the usual suspects: Knowledge-based metaphor generation. In Proceedings of the Fourth Workshop on Metaphor in NLP.

Jean-Paul Vinay and Jean Darbelnet. 1995. Comparative stylistics of French and English: A methodology for translation, volume 11. John Benjamins Publishing.

Ellen M Voorhees. 1999. The TREC-8 question answering track report. In Proceedings of the Text REtrieval Conference, volume 99.

Denny Vrandečić and Markus Krötzsch. 2014. Wikidata: a free collaborative knowledgebase. Соттиnications of the ACM, 57(10):78-85.

Eric Wallace, Pedro Rodriguez, Shi Feng, Ikuya Yamada, and Jordan Boyd-Graber. 2019. Trick me if you can: Human-in-the-loop generation of adversarial question answering examples. Transactions of the Association of Computational Linguistics, 10. 


\section{A Appendix}

Our appendix contains our entire human-collected dataset, as well as a sample of our WikiData and embedding approaches for adaptation.

Figure 2 shows our collection tool. Table 3 shows German $\rightarrow$ American Veale NOC items. Table 4 shows American $\rightarrow$ German Veale NOC items. Table 5 shows German $\rightarrow$ American Veale NOC items. Table 6 shows American $\rightarrow$ German Veale NOC items.

Table 7 shows our WikiData predictions, Table 8 shows our 3CosAdd predictions. and Table 9 shows our Learned Adaptations predictions. We pose several background questions about Wikipedia and WikiData as well:

\section{B Wikipedia Analysis}

Are the Wikipedia pages in German and English visited from the associated country? Yes; the Wikipedias for the respective languages are most used by visitors located in those countries: $63 \%$ of German wikipedia was visited from Germany and 32\% of English Wikipedia was visited from the United States in the past year. ${ }^{9}$

Are the top Wikipedia topics notably different across languages? Yes; less than a quarter of top 500 searches for 2019 are identical across English and German.

Does WikiData cover areas outside of the United States? Wikipedia coverage does not mean that WikiData annotations are conducted equally across German and American entities. Analyzing WikiData ${ }^{10}$ reveals a discrepancy in coverage of Germans and Americans.

Out of 8,126,559 titles, 1,030,762 include a reference to the United States in any capacity. However, only 184,692 contain a reference to (broader) Germany. This imbalance is significant but has enough German items for our methodology. As WikiData is a maintained resource, there is room for future additional coverage and standardization of fields.

Countries use different names throughout history. While the United States of America is straightforward, Germany includes several variations, such as: German Empire, the Kingdom of Bavaria, the Kingdom of Prussia, etc. The WikiData feature-based approach can be used for other countries as well (... or anything that is consistently coded). For example, there are 65,957 Russian, 152,701 French, and 48,026 Chinese items in WikiData. ${ }^{11}$

Are the top Wikipedia topics necessarily belonging to the culture? No; the top 10 most visited German Wikipedia includes a cultural potpurri: Germany, Greta Thurnberg, Asperger Syndrome, Game of Thrones, and Freddie Mercury. While there are uniquely German entities in the longer list-ZDF, Capital Bra, The Cratez, Niki Lauda - we cannot conclude that all top entities in a language belong culturally to a given country. Therefore, we need a stricter methodology.

Where does one find entities? We rely on a human-sourced dataset: Veale's Non-Official Characterization list (Veale, 2016). This list contains 1031 people, real and fictional, such as Daniel Day-Lewis, Anton Chekhov, and Bridget Jones. These people are annotated with properties, one of which is conveniently their address. There are 25 people with a German location and 575 with an American one. Removing fictional characters written by non-nationals causes the German leaves the list with 20 entities. An American author filters the list of Americans down to 35 iconic ones with achievements that span politics, music, activism, athletics, and pop culture.

Wikipedia provides another avenue for gauging popular topics in a language. We manually filter the top 500 German/English Wikipedia topics to remove non-German/non-American entities; Game of Thrones and Unix-Shell are popular in the German Wikipedia, but they are not culturally idiosyncratic. For the 2019 German Wikipedia we are left with roughly 200 items, which we further reduce down to 120

\footnotetext{
${ }^{9} \mathrm{https}: / /$ stats.wikimedia.org/

${ }^{10}$ we use a full 1.2 Terabyte dump as of 10.26.20

${ }^{11}$ the modern day name countries only
} 
after putting a cap on pop culture entities. For the American counterpart, over 300 items are culturally American. We add a three-year filter to remove pop items to make it comparable to the German one.

\section{Interfaces}

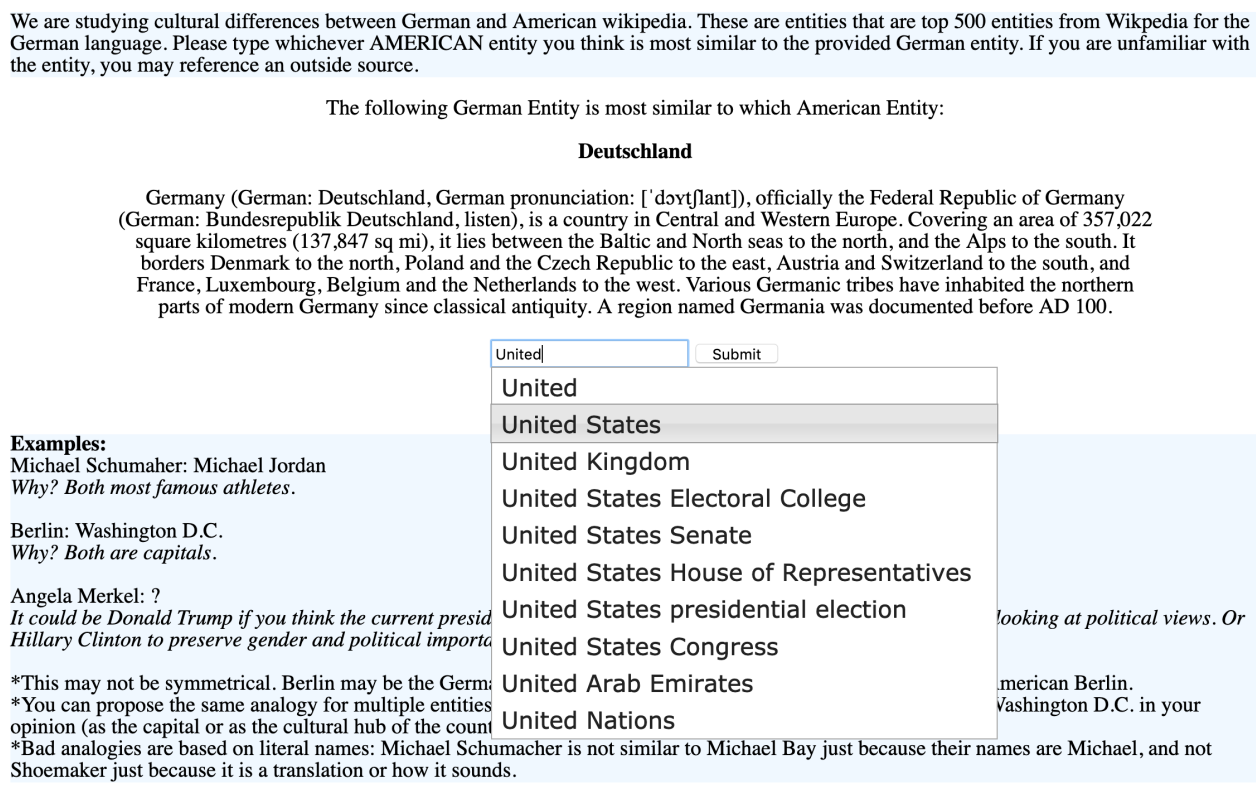

Figure 2: Our interface provides users with information about the entity and asks them to select an option from possible Wikipedia pages

Compare the below German entities to this American entity: Abraham Lincoln / Abraham Lincoln was an American statesman and lawyer who served as the 16th president of the United States from 1861 until his assassination in 1865.

click for Instructions

Konrad Adenauer / Konrad Hermann Joseph Adenauer was a German statesman who served as the first Chancellor of the Federal Republic of Germany from 1949 to 1963.

Helmut Schmidt / Helmut Heinrich Waldemar Schmidt was a German politician and member of the Social Democratic Party of Germany , who served as Chancellor of the Federal Republic of Germany from 1974 to 1982 .

Willy Brandt / Willy Brandt was a German politician and statesman who was leader of the Social Democratic Party of Germany from 1964 to 1987 and served as Chancellor of the Federal Republic of Germany from 1969 to 1974.

Helmut Kohl / Helmut Josef Michael Kohl was a German statesman and politician of the Christian Democratic Union who served as Unrelated Slightly Somewhat Somewhat Very Related Related Similar Similar Chancellor of Germany from 1982 to 1998 and as chairman of the CDU from 1973 to 1998.

Figure 3: Our Qualtrics survey 


\section{Data}

Entity

Adolf Eichmann

Angela Merkel

Baron Munchausen

Carl von Clausewitz

Friedrich Nietzsche

Henry Kissinger

Immanuel Kant

Johann Sebastian Bach

Johann Wolfgang von Goethe

Johannes Gutenberg

Joseph Goebbels

Karl Lagerfeld

Karl Marx

Leni Riefenstahl

Ludwig van Beethoven

Marlene Dietrich

Martin Luther

Otto von Bismarck

Pope Benedict XVI

Richard Wagner

\section{Human Adaptation: NOC German $\rightarrow$ American}

Andrew Jackson, Andrew Jackson, Franklin D. Roosevelt, Nathan Bedford Forrest, Steve Bannon

Barack Obama, Donald Trump, Hillary Clinton, Hillary Clinton, Hillary Clinton, Hillary Clinton, Joe Biden

Captain America, Daniel Bolger, Joseph Smith, Paul Bunyan, Robert Jordan, Yankee Doodle

Alfred Thayer Mahan, Dwight D. Eisenhower, Henry Knox, Robert E. Lee, Ulysses S. Grant

Ayn Rand, Henry David Thoreau, Henry Thoreau, Jordan Peterson, William James

Henry Kissinger, Henry Kissinger, John Kerry, Madeleine Albright, Richard Nixon

Benjamin Franklin, John Dewey, John Locke, John Rawls, Robert Nozick

Aaron Copland, Elvis Presley, Elvis Presley, Irving Berlin, Johnny Cash, Scott Joplin

Edgar Allan Poe, Ernest Hemingway, Walt Whitman

Benjamin Franklin, Bill Gates, Eli Whitney, Thomas Edison

David Duke, Franklin D. Roosevelt, George Rockwell, Rupert Murdoch, david duke

Anna Wintour, Anna Wintour, Marc Jacobs, Ralph Lauren, Ralph Lauren, Ralph Lauren, Ralph Lauren

Angela Davis, Beck, Bernie Sanders, John Jay, John Rawls, John Rawls

DW Griffeth, David Wark Griffith, Frank Capra, Judy Garland

Aaron Copland, Aaron Copland, Aaron Copland, Elvis Presley, Frank Sinatra, George Gershwin, George Gershwin, Scott Joplin Bette Davis, Clara Bow, Elizabeth Taylor, Marilyn Monroe, William Tecumseh Sherman

Barry Goldwater, Brigham Young, Joseph Smith, Joseph Smith, Joseph Smith

Abraham Lincoln, George Washington, George Washington, George Washington, George Washington, Ulysses S. Grant

Billy Graham, Billy Graham, Brigham Young, John Carroll , Seán Patrick O'Malley

Charles Ives, Frank Sinatra, Leonard Bernstein, Philip Glass

Table 3: Veale NOC German $\rightarrow$ American adaptations. 
Abraham Lincoln

Al Capone

Alfred Hitchcock

Benedict Arnold

Bill Gates

Britney Spears

Charles Lindbergh

Donald Trump

Elvis Presley

Ernest Hemingway

Frank Lloyd Wright

George Washington

Henry Ford

Hillary Clinton

Homer Simpson

Jack The Ripper

Jay Z

Jimi Hendrix

John F. Kennedy

Kim Kardashian

Louis Armstrong

Marilyn Monroe

Michael Jordan

Neil Armstrong

Noam Chomsky

Oprah Winfrey
Helmut Kohl, Konrad Adenauer, Wilhelm Friedrich Ludwig von Preußen, Willy Brandt, Willy Brandt

Adolf Leib, Carlos Lehder-Rivas, Jan Marsalek, Nasser AbouChaker, Nasser About-Chaker

Bernd Eichinger, Bernd Eichinger, Michael Bully Herbig, Roland Emmerich, Wim Wenders

Hansjoachim Tiedge, Otto von Bismarck, Otto von Bismarck, Robert Blum

Andreas von Bechtolsheim, Carl Benz, Dietmar Hopp, Konrad Zuse

Helene Fischer, Herbert Grönemeyer, Jeanette Biedermann, Nena, Til Schweiger

Ferdinand von Richthofen, Heinrich Horstman, Karl Wilhelm Otto Lilienthal, Ludwig Hofmann, Wernher von Braun

Adolf Hitler, Adolf Hitler, Carsten Maschmeyer, Christian Lindner Peter Kraus, Rammstein, The Scorpions, Udo Lindenberg, Udo Lindenberg

Günter Grass, Hermann Hesse, Johann Wolfgang von Goethe, Karl May, Martin Walser

Gerhard Richter, Hugo Häring, Karl Lagerfeld, Max Dudler, Walter Gropius

Friedrich II, Heinrich I, Konrad Adenauer, Otto I. der Große, Otto von Bismarck

Carl Benz, Carl Benz, Carl Benz, Ferdinand Porsche, Gottlieb Wilhelm Daimler

Angela Merkel, Angela Merkel, Angela Merkel, KrampKarrenbauer, Sahra Wagenknecht

Alf, Heidi, Pumuckl, Werner, Werner - Beinhart!

Armin Meiwes, Der Bulle von Tölz, Joachim Kroll, Karl Denke, Rudolf Pleil

Capital Bra, Marteria, Sido, Sido, Sido

Bela B., Gisbert zu Knyphausen, Herbert Grönemeyer, Rudolf Schenker, Spider Murphy Gang

Hanns Martin Schleyer, Willy Brandt, Willy Brandt, Wolfgang Schäuble

Carmen Geiss, Gina-Lisa Lohfink, Heidi Klum, Heidi Klum, Sarah Connor

Günter Sommer, Helmut Brandt, Jan Delay, Michael Abene, Mozart

Heidi Klum, Ingrid Steeger, Marlene Dietrich, Micaela Schäfer, Uschi Glas

Dirk Nowitzki, Dirk Nowitzki, Dirk Nowitzki, Franz Beckenbauer, Michael Schuhmacher

Alexander Gerst, Sigmund Jähn, Sigmund Jähn, Ulf Merbold, Wernher von Braun

Helmut Glück, Juergen Habermas, Jürgen Habermas, Ludwig Wittgenstein, Wilhelm Röntgen

Anne Will, Arabella Kiesbauer, Maybrit Illner, Thomas Gottschalk, Thomas Gottschalk 
Orville Wright

Richard Nixon

Rosa Parks

Serena Williams

Steve Jobs

Steven Spielberg

Superman

Tiger Woods

Walt Disney
Carl Benz, Gustav Otto, Gustav Weißkopf, Otto Lilienthal, Wernher von Braun

Franz Josef Strauss, Helmut Kohl, Ludwig Erhard, Ludwig Erhard, Richard von Weizsäcker

Anne Wizorek, Marie Juchacz, Sophie Scholl, Sophie Scholl, Vera Lengsfeld

Andrea Petkovic, Boris Becker, Sabine Lisicki, Steffi Graf, boris becker

Carl Benz, Dietmar Hopp, Dietmar Hopp, Karl Lagerfeld

Michael Bully Herbig, Roland Emmerich, Roland Emmerich, Roland Emmerich, Wim Wenders

Bibi Blocksberg, Fix and Foxi, Maverick, Superman, Till Eulenspiegel

Boris Becker, Martin Kaymer, Martin Kaymer, Michael Schumacher, Serge Gnabry

Axel Springer, Christian Becker, Franz Mack, Gerhard Hahn, Rötger Feldmann

Table 4: Veale NOC American $\rightarrow$ German adaptations. 


\begin{tabular}{|c|c|}
\hline Entity & Human Adaptation: Wikipedia German $\rightarrow$ American \\
\hline ARD & NPR, PBS, PBS \\
\hline Adolf Hitler & $\begin{array}{l}\text { Donald Trump, Donald Trump, Franklin D. Roosevelt, Franklin D. } \\
\text { Roosevelt, Franklin D. Roosevelt }\end{array}$ \\
\hline Airbus & Boeing, Boeing, Boeing, Boeing, Lockheed Martin \\
\hline Albert Einstein & $\begin{array}{l}\text { Carl Sagan, J. Robert Oppenheimer, J. Robert Oppenheimer, John } \\
\text { Forbes Nash Jr., Thomas Edison }\end{array}$ \\
\hline Alice Merton & Ariana Grande, Elle King, K.T. Tunstall, P!NK, Vanessa Carlton \\
\hline Alternative für Deutschland & Libertarian Party, Republican Party, Tea Party movement \\
\hline Andrea Nahles & $\begin{array}{l}\text { Elizabeth Warren, Hillary Clinton, Nancy Pelosi, Tammy Duck- } \\
\text { worth }\end{array}$ \\
\hline Andrej Mangold & Kawhi Leonard, Kevin Durant, Kris Humphries, Yao Ming \\
\hline Annalena Baerbock & $\begin{array}{l}\text { Al Gore, Al Gore, Alexandria Ocasio-Cortez, Bernie Sanders, Jill } \\
\text { Stein }\end{array}$ \\
\hline Anne Frank & Anna Green Winslow, Clara Barton, Emmett Till, Kunta Kinte \\
\hline Annegret Kramp-Karrenbauer & Condoleezza Rice, Hillary Clinton \\
\hline AnnenMayKantereit & $\begin{array}{l}\text { Guns N' Roses, Milky Chance, Polar Bear Club, Red Hot Chili } \\
\text { Peppers }\end{array}$ \\
\hline Apache 207 & Fetty Wap, Tekashi 69, XXXTentacion, Zayn Malik \\
\hline Arnold Schwarzenegger & $\begin{array}{l}\text { Chuck Norris, Dwayne Johnson, Ronnie Coleman, Sylvester Stal- } \\
\text { lone, Sylvester Stallone }\end{array}$ \\
\hline BMW & Cadillac, Cadillac, Chevrolet, Chrysler \\
\hline Babylon Berlin & $\begin{array}{l}\text { Game of Thrones, Man From U.N.C.L.E., Peaky Blinders, The } \\
\text { Americans, Turn }\end{array}$ \\
\hline Baden-Württemberg & $\begin{array}{l}\text { California, Chicago metropolitan area, San Diego, Southern } \\
\text { United States, Texas }\end{array}$ \\
\hline Bastian Yotta & Chad Johnson, Colton Underwood, Dan Bilzerian \\
\hline Bauhaus & Frank Lloyd Wright \\
\hline Bayerischer Rundfunk & $\begin{array}{l}\text { NPR, National Public Radio, National Public Radio, national } \\
\text { public ra }\end{array}$ \\
\hline Bayern & Florida, New York, The Confederacy \\
\hline Benjamin Piwko & Bruce Lee, Colton Underwood, Derek Hough \\
\hline Berlin & $\begin{array}{l}\text { New York City, Portland Oregon, Washington D.C., Washington } \\
\text { D.C., Washington D.C. }\end{array}$ \\
\hline Berliner Mauer & $\begin{array}{l}\text { Border Patrol Police, Mason-Dixon line, Mason-Dixon line, US- } \\
\text { Mexican border }\end{array}$ \\
\hline Bertolt Brecht & Tennessee Williams, Tennessee Williams \\
\hline Björn Höcke & Lindsey Graham, Mike Pence \\
\hline Borussia Dortmund & $\begin{array}{l}\text { Golden State Warriors, New England Patriots, New England Patri- } \\
\text { ots }\end{array}$ \\
\hline Brandenburg & $\begin{array}{l}\text { Maryland, New York, Northeastern United States, Richmond Vir- } \\
\text { ginia, Virginia }\end{array}$ \\
\hline Bruno Ganz & $\begin{array}{l}\text { Clint Eastwood, Ethan Hawke, Marlon Brando, Robert De Niro, } \\
\text { Robert De Niro }\end{array}$ \\
\hline Bundespräsident & First Lady, President of the United States, Speaker of the House \\
\hline Bundeswehr & $\begin{array}{l}\text { Department of Defense, US military, United States Armed Forces, } \\
\text { United States Army }\end{array}$ \\
\hline Capital Bra & Drake, Eminem, Eminem, Kanye West, Kendrick Lamar \\
\hline Carola Rackete & $\begin{array}{l}\text { American Civil Liberties Union, Dawn Wooten, Rosa Parks, } \\
\text { Whale Wars }\end{array}$ \\
\hline Carolin Kebekus & Amy Schumer, Sarah Silverman, Tina Fey, Tina Fey \\
\hline
\end{tabular}


Charité

Chris Töpperwien

Christoph Waltz

Dark

Deutsche Bahn

Deutsche Demokratische Repub-

lik

Deutsche Nationalhymne

Deutschland

Dieter Bohlen

Dirk Nowitzki

Doreen Dietel

Dreißigjähriger Krieg

Elisabeth von Österreich-Ungarn

Elyas M'Barek

Europawahl in Deutschland 2019

Europäisches Parlament

Evelyn Burdecki

FC Bayern München

Falco

Ferdinand Sauerbruch

Flughafen Berlin Brandenburg

Frankfurt am Main

Fritz Honka

Hamburg

Hannelore Elsner

Heidi Klum

Heinz-Christian Strache

Helene Fischer

Hessen

Holocaust

Ich bin ein Star - Holt mich hier raus!

Jürgen Klopp

Kevin Kühnert
Call the Midwife, Grey's Anatomy, Grey's Anatomy, The Queen's Gambit

Gordon Ramsey , Guy Fieri, Jeff Probst

Anthony Hopkins, Christoph Waltz, Denzel Washington

Stranger Things, Stranger Things

Amtrack, Norfolk Southern Railway, Union Pacific Corporation

Confederate States of America, Confederate States of America, Texas, The Confederacy, The Confederate States of America

Born in the U.S.A., Lazy Eye, Star Spangled Banner, The Star Spangled Banner

America, America, Continental United States, USA, United States, United States

Billy Joel, Blake Shelton, Daryl Hall, Paula Abdul, Ryan Seacrest LeBron James, Michael Jordan, Shaquille O’Neal

Jessica Alba, Lisa Kudrow, Warrick Brown

American Civil War, American Civil War, American Indian Wars, Civil war

Edith Roosevelt, Hillary Clinton, Jackie Kennedy

Adam Sandler, Adam Sandler, Chris Pine

2018 United States elections, American presidential election 2020, Us election 2018

North Atlantic Council, Representative of the United States of America to the European Union, United Nations, United States Congress

Hannah Brown, Kaitlyn Bristowe, Kim Kardashian, Kim Kardashian

Dallas Cowboys, Dc United, New York Yankees, New York Yankees, New York Yankees

David Bowie, Frederick William Schneider III, MC Hammer, Michael Jackson

Ben Carson, Ben Carson, Cornelius P. Rhoads, Jonas Salk, Virginia Apgar

Cincinnati Subway, DCA, John F. Kennedy International Airport, LaGuardia Airport

Chicago, Los Angeles, Los Angeles, New York City, Washington

D.C.

Ted Bundy, Ted Bundy, Ted Bundy, Zodiac

Chicago, Chicago, Los Angeles, New York, Philadelphia

Elizabeth Taylor, Jane Lynch, Julia Roberts

Chrissy Teigen, Cindy Crawford, Gigi Hadid, Karlie Kloss, Tyra

Banks

Anthony Weiner, Ben Carson, Donald J. Trump, Rob Ford, Roger

Stone

Beyoncé, Kelly Clarkson, Taylor Swift, Taylor Swift

Arizona, Illinois, Mid-Atlantic , Napa County California

Chattel Slavery, Japanese interned in American camps, Slavery in the United States

Survivor, Survivor

Bill Belichick, Bill Belichick, John Wooden

Bernie Sanders, Bernie Sanders, Bernie Sanders, Pete Buttigieg 
Klaus Kinski

\author{
Kontra K \\ Köln \\ Leila Lowfire \\ Leipzig \\ Lena Meyer-Landrut \\ Liechtenstein \\ Lisa Martinek \\ Ludwig van Beethoven
}

Lufthansa

Luxemburg

Mark Forster

Mero

Michael Schumacher

München

Nico Santos

Niki Lauda

Norddeutscher Rundfunk

Nordrhein-Westfalen

Philipp Amthor

RAF Camora

Rammstein

Rhein

Robert Habeck

Rudi Assauer

Sahra Wagenknecht

Sarah Connor

Schweiz

Sebastian Kurz

Serge Gnabry

Sido

The Cratez

Thüringen

Till Lindemann

Tom Kaulitz

UEFA Champions League

Udo Jürgens

Udo Lindenberg
Christopher Lee, Clark Gable, John Wayne, Robert Pattinson, Robert Pattinson

50 Cent, Eminem, Eminem, Jesus Is King, Travis Scott

Boston, Chicago, Chicago, Houston

Paris Hilton, Sasha Grey, Zendaya

Denver, Detroit, Miami, San Diego

Ariana Grande, Kelly Clarkson, Kelly Clarkson, Meghan Trainor, Selena Gomez

Connecticut, Mexico, Philippines, Victoria British Columbia

Julie Benz, Katherine Heigl, Mandy Moore, Meryl Streep

Aaron Copland, Aaron Copland, Aaron Copland, Aaron Copland, Elvis Presley, Frank Sinatra, George Gershwin, George Gershwin, Scott Joplin

Delta, United, United Airlines, United Airlines

Canada, Connecticut, Mexico, Victoria British Columbia

Bruno Mars, Post Malone

DaBaby, Fetty Wap, Lil Nas X, Lil Nas X, Post Malone

Dale Earnhardt, Dale Earnhardt, James Gordon, Jeff Gordon, Tiger Woods

Chicago, Los Angeles, New York City, New York City, Washington D.C.

Harry Styles, Justin Bieber, Shawn Mendes

Dale Earnhardt, Dale Earnhardt Jr., Jeff Gordon, Jeff Gordon, Tiger Woods

NPR, NPR, National Public Radio, PBS, Sirius XM

California, California

Alexandria Ocasio-Cortez, Ben Shapiro

Bad Bunny, Drake, Drake, Eminem, Future

Green Day, Metallica, Metallica, Metallica, Sum 41

Mississippi, Mississippi River, Mississippi River

Al Gore, Bernie Sanders, Jill Stein, Ralph Nader

Dave Roberts, Gregg Berhalter, Tom Flores, Vince Lombardi, Vince Lombardi

Alexandria Ocasio-Cortez, Elizabeth Warren, Elizabeth Warren, Elizabeth Warren, Nancy Pelosi

Beyoncé, Britney Spears, Mariah Carey

Canada, Canada, Iowa, Mexico, United States

Alexandria Ocasio-Cortez, Greg Abbott, Justin Trudeau, Justin Trudeau, Mitch McConnell

Clint Dempsey, JuJu Smith-Schuster, Phillip Rivers, Stephen

Curry, Zion Williamson

Eminem, Eminem, Macklemore

DJ Khaled, Drake, Twenty One Pilots

Iowa, Midwestern United States, Tennessee, Tennessee

James Hetfield, James Hetfield, James Hetfield, Ozzy Osbourne

Adam Levine, Blink-182, Chris Martin, Green Day, Maroon 5

Major League Soccer, NFC, NFL, National Football League, Ncaa

Aretha Franklin, Billy Joel, Elton John, Michael Jackson, Rolling

Stone, Tom Lehrer

Johnny Cash, Mick Jagger, Roger Taylor , Travis Barker 
Ursula von der Leyen

Volkswagen AG

Walter Lübcke

Weimarer Republik

Westdeutscher Rundfunk Köln

Wien

Wilhelm II.

Wolfgang Amadeus Mozart

ZDF

Österreich

Ötzi
Condoleezza Rice, Hillary Clinton, Mike Pence, Sarah Palin, Susan Rice

Ford Motor Company, Ford Motor Company, Ford Motor Company, Ford Motor Company, Ford Motor Company

Harvey Milk, John F. Kennedy, John Roll, Steve Scalise

America, Confederation Period, Congress of the Confederation,

Counterculture of the 1960s, The Confederate States of America ABC News, NBC, NPR

Austin Texas, Richmond Virginia, Toronto, Washington D.C.

William Howard Taft, Woodrow Wilson, Woodrow Wilson

Alan Menken, Elvis Presley, Leonard Bernstein

NPR, NPR, National Public Radio, PBS, PBS

Canada, Mexico, Texas, Texas, United States

Spirit Cave mummy, Spirit Cave mummy, Spirit Cave mummy, Sue

Table 5: Top Wikipedia German $\rightarrow$ American adaptations. 
13 Reasons Why

Albert Einstein

Alexander Hamilton

American Civil War

American Horror Story

Angelina Jolie

Apple Inc.

Ariana Grande

Arnold Schwarzenegger

Ashton Kutcher

Australia

Avengers Infinity War

Barack Obama

Beyoncé

Black Mirror

Blake Lively

Brad Pitt

Bruce Lee

Caitlyn Jenner

California

Camila Cabello

Canada

Cardi B

Charles Manson

Charlize Theron

Cher

Chris Pratt

Clint Eastwood

Darth Vader

Donald Glover

\section{Human Adaptation: Wikipedia American $\rightarrow$ German}

Club der roten Bänder, Gute Zeiten schlechte Zeiten, Lammbock, Türkisch für Anfänger

Albert Einstein, Albert Einstein, Albert Einstein, Max Planck, Max Planck

Konrad Adenauer, Max Weber, Otto von Bismarck, Otto von Bismarck

Deutscher Krieg, Dreißigjähriger Krieg, German Revolution of 1918-1919, German revolutions of 1848-1849

Dark, Der goldene Handschuh, Good Bye Lenin!, Tintenherz

Barbara Schöneberger, Franka Potente, Marlene Dietrich, Romy

Schneider, Veronica Maria Cäcilia Ferres

BMW, Fujitsu, SAP, Siemens

Lena Meyer-Landrut, Lena Meyer-Landrut, Lena Meyer-Landrut, Sarah Connor, Sarah Connor

Arnold Schwarzenegger, Karl Lauterbach, Matthias Steiner, Peter Maffay, Ralf Rudolf Möller

Florian David Fitz, Matthias Schweighöfer, Til Schweiger, Til Schweiger

Australia, Russia, Schweiz, South Africa, Österreich

Das Arche Noah Prinzip, Fack ju Göhte, Fantastic Four, Who Am I

Angela Merkel, Angela Merkel, Angela Merkel, Helmut Schmidt, Helmut Schmidt

Helene Fischer, Sarah Connor, Veronica Ferres, Xavier Naidoo, Yvonne Catterfeld

Dark, Dark, Die kommenden Tage, Krabat

Josefine Preuß, Maria Furtwängler, Maria Furtwängler, Til Schweiger

Florian David Fitz, Frederick Lau, Til Schweiger, Til Schweiger, Til Schweiger

Götz Georg, Henry Maske, Julian Jacobi, Max Schmeling, no one is like Bruce Lee

Kristin Otto, Magdalena Neuner, Magdalena Neuner, Niklas Kaul, Ulrike Meyfarth

Bavaria, Bavaria, Bayern, Bayern

Helene Fischer, Lena Meyer-Landrut, Lena Meyer-Landrut, Nadja

Benaissa

Austria, Italy, Schweiz, Sweden, Österreich

Ace Tee, Pamela Reif, Sabrina Setlur, Sarah Connor, Schwester

Ewa

Andreas Baader, Issa Rammo, Papst benedikt xvi, Paul Schäfer

Baran bo Odar, Josefine Preuß, Josefine Preuß, Veronica Ferres, Veronica Maria Cäcilia Ferres

Marlene Dietrich, Nena, Nena, Nena

Elyas M'Barek, Jan Josef Liefers, Matthias Schweighöfer, Ralf Moeller, Til Schweiger

Heinz Erhardt, Klaus Kinski, Mario Adorf, Til Schweiger, Wim Wenders

Adolf Hitler, Belzebub, Hagen von Tronje, Jens Maul

Elyas M'Barek, Helge Schneider, Money Boy, Stefan Raab 
Drake

Dwayne Johnson

Elon Musk

Eminem

Facebook

Friends

Game of Thrones

Google

Harry Potter

Heath Ledger

It

Jason Momoa

Jeff Bezos

Jeffrey Dahmer

Jennifer Aniston

Jennifer Lawrence

Jennifer Lopez

John Cena

Johnny Cash

Johnny Depp

Julia Roberts

Justin Bieber

Keanu Reeves

Kylie Jenner

Lady Gaga

LeBron James

Leonardo DiCaprio

Lisa Bonet

Madonna

Mark Wahlberg

Martin Luther King Jr.
Bushido, Cro, Falco, Fler

Alexander Wolfe, Arnold Schwarzenegger, Peter Alexander, Tim Wiese, Tim Wiese

Alexander Samwer, August Horch, Carl Benz, Herbert Diess, Werner von Siemens

Bushido, Kollegah, Sido, Sido, Sido

Das Erste, Lokalisten, Lokalisten, Schüler VZ, StudiVZ, StudiVZ

Gute Zeiten schlechte Zeiten, Gzsz, Lindenstraße, Stromberg

Babylon Berlin, Babylon Berlin, Babylon Berlin, Die unendliche Geschichte, Krabat

Ecosia, Fastbot, SAP, SAP, i.d.k.

Die Unendliche Geschichte, Die unendliche Geschichte, Harry

Potter und ein Stein, Meggie Folchart

Christoph Waltz, Florian David Fitz, Henry Blanke, Matthias

Schweighöfer, Tilman Valentin Schweiger

Dark, Der goldene Handschuh, Die Wolke, Pandorum

Arnold Schwarzenegger, Benno Fürmann, Christoph Waltz, Elyas

M'Barek, Elyas M'Barek, Elyas M'Barek

Alexander Samwer, Beate Heister, Martin Winterkorn, Oliver Samwer

Armin Meiwes, Fritz Haarmann, Joachim Kroll, Karl Denke, Karl Denke

Barbara Schöneberger, Diane Kruger, Diane Kruger, Franka Potente, Iris Berben

Iris Berben, Josefine Preuß, Karoline Herfurth, Ruby O. Fee

Heidi Klum, Helene Fischer, Jeanette Biedermann, Mandy Capristo, Sarah Connor

Arnold Schwarzenegger, Max Schmeling, Max Schmeling, Ralf Möller

Fantastischen vier, Helge Schneider, Peter Maffay, Peter Maffay

Christoph Maria Herbst, Christoph Waltz, Cro, Til Schweiger,

Xavier Naidoo

Karoline Herfurth, Maria Furtwängler, Marlene Dietrich, Marlene

Dietrich

Cro, Felix Jaehn, Lukas Rieger, McFittie, Mike Singer

Daniel Brühl, Mario Adorf, Til Schweiger, til schweiger

Barbara Schöneberger, Heidi Klum, Karoline Einhoff, Sarah Connor, Stefanie Giesinger

Helene Fischer, Nena, Nena, Nina Hagen, Sarah Lombardi

Dirk Nowitzki, Dirk Nowitzki, Dirk Nowitzki, Dirk Nowitzki, Toni Kroos

Matthias Schweighöfer, Moritz Bleibtreu, Til Schweiger, Til

Schweiger, Til Schweiger

Franka Potente, Iris Berben, Karoline Herfurth, Maria Furtwängler

Blümchen, Helene Fischer, Helene Fischer, Helene Fischer, Sarah

Connor

Florian David Fitz, Til Schweiger, Tilman Valentin Schweiger, Alexei Alexejewitsch

Hans Scholl, Hans Scholl, Helmut Palmer, Robert Blum, Sophie Scholl 
Marvel Cinematic Universe

Michael Jackson

Mila Kunis

Miley Cyrus

Muhammad Ali

Natalie Portman

New York City

Nicole Kidman

Peaky Blinders

Philippines

Post Malone

Rihanna

Riverdale

Robert Downey Jr.

Robin Williams

Ronald Reagan

Ryan Reynolds

Scarlett Johansson

Selena Gomez

September 11 attacks

Shaquille O'Neal

Star Wars

Stephen Curry

Stranger Things

Sylvester Stallone

Taylor Swift

Ted Bundy

The Big Bang Theory

The Crown

The Handmaid's Tale

The Walking Dead

Tom Brady

Tom Cruise

Tom Hanks
Bavaria Film, Havelstudios, Phantásien, Rat Pack Filmproduktion, Tatort

Herbert Grönemeyer, Nena, Udo Jürgens, Xavier Naidoo, Xavier Naidoo

Josefine Preuß, Matthias Schweighöfer, Vanessa Mai

Lena Meyer-Landrut, Lukas Rieger, Nena, Sarah Connor, Yvonne Catterfeld

Alexander Abraham, Boris Becker, Max Schmeling, Max Schmeling, Sven Ottke

Barbara Schöneberger, Diane Kruger, Franka Potente, Iris Berben Berlin, Berlin, Berlin, Berlin, Frankfurt

Evelyn Hamann, Franka Potente, Senta Berger, iris berben

Dark, Dieter Schwarz, Im Westen Nichts Neues, Tatort, Tatort

Greece, Griechenland, Mallorca, Mallorca

Bushido, Bushido, Cro, Cro, Kollegah

Helene Fischer, Lena Meyer-Landrut, Lena Meyer-Landrut, Nena

Babylon Berlin, Berlin Tag und Nacht, Neues vom Süderhof, Türkisch für Anfänger

Christoph Waltz, Günter Strack, Martin Semmelrogge, Moritz Bleibtreu, Til Schweiger

Hape Kerkeling, Heinz Erhardt, Peter Maffay, Silvia Seidel, Tim Bendzko

Helmut Schmidt, Konrad Adenauer, Konrad Adenauer, Konrad Adenauer

Daniel Brühl, Florian David Fitz, Matthias Schweighöfer, Til

Schweiger, Til Schweiger

Lena Gercke, Romy Schneider, Sarah Connor, Sarah Connor, Veronica Ferres

Lena Meyer-Landrut, Lena Meyer-Landrut, Nena, Nora Tschirner Anschlag im OEZ, Dresden Bombing, Mauerfall, RAF-Attentate, Terroranschlag Olympia 1972

Dirk Nowitzki, Dirk Nowitzki, Mehmet Scholl, Niklas Süle

Dark, Metropolis, Traumschiff Surprise - Periode 1, Who Am I?, i.d.k

Dirk Nowitzki, Dirk Nowitzki, Dirk Nowitzki, Dirk Nowitzki, Manuel Neuer

8 Tage, Babylon Berlin, Dark, Tatort, Tatort

Henry Blanke, Jan Josef Liefers, Michael Bully Herbig, Michael Fassbender, Til Schweiger

Lena Meyer-Landrut, Lena Meyer-Landrut, Sarah Connor, Sarah Connor, Yvonne Catterfeld

Joachim Kroll, Josef Fritzl, Niels Högel, Rudolf Pleil, Rudolf Pleil Doctor's Diary, Stromberg, Stromberg, der Tatortreiniger

Babylon Berlin, Deutschland 83, Die Deutschen, Karl der Große

Dark, Dark, Der Pass, Die Wanderhure, Er ist wieder da

Dark, Dark, Der goldene Handschuh, Zombies From Outer Space

Franz Beckenbauer, Michael Ballack, Oliver Kahn, Thomas Müller, Uli Stein

Benno Fürmann, Benno Fürmann, Christoph Waltz, Elyas M'Barek, Matthias Schweighöfer

Christoph Waltz, Christoph Waltz, Daniel Brühl, Til Schweiger 
Tom Hardy

Tom Holland

Tupac Shakur

United States

Vietnam War

Wikipedia

Will Smith

$\mathrm{X}-\mathrm{Men}$

YouTube

Zac Efron

Zendaya
Bruno Ganz, Michael Herbig, Til Schweiger, Wotan Wilke Möhring

Daniel Brühl, Frederick Lau, Matthias Schweighöfer, Matthias Schweighöfer, Til Schweiger

Farid Bang, Haftbefehl, Kollegah, Kristoffer Klauß, Peter Fox

BRD, Bundesrepublik Deutschland, Deutschland, Germany, Germany

Berlin Wall, First world war, Kosovokrieg, World War II

Brockhaus, Brockhaus Enzyklopädie, Brockhaus Enzyklopädie, Duden, dict.cc

Daniel Brühl, Elyas M'Barek, Sascha Reimann, Sido, Til Schweiger

Abwärts, Fantastic Four, Freaks, Krabat, Who Am I

Lokalisten, MyVideo, MyVideo, ProSieben, lokalisten

Frederick Lau, Lukas Rieger, Peter Kraus, Walter Sedlmayr

Franka Potente, Iris Berben, Lena Meyer-Landrut, Lena Meyer-

Landrut, Yvonne Catterfeld

Table 6: Top Wikipedia American $\rightarrow$ German adaptations. 
Abraham Lincoln

Al Capone

Alfred Hitchcock

Benedict Arnold

Bill Gates

Britney Spears

Donald Trump

Elvis Presley

Ernest Hemingway

Frank Lloyd Wright

George Washington

Henry Ford

Hillary Clinton

Homer Simpson

Jimi Hendrix

Kim Kardashian

Marilyn Monroe

Michael Jordan

Louis Armstrong

Neil Armstrong

Noam Chomsky

Oprah Winfrey

Orville Wright

Richard Nixon

Superman

\section{Top Five WikiData Adaptations}

Victor Adler, Johann Joachim Christoph Bode, Willem Barentsz, Hermann Wagener, Robert von Mohl

Hans H. Zerlett, Fritz Thyssen, Adam Rainer, Franz Winkelmeier, Christian Louis, Duke of Brunswick-Lüneburg

Edgar Reitz, Jan Josef Liefers, Mario Adorf, Max Frisch, Armin Mueller-Stahl

Hans-Georg Hess, Isabelle Eberhardt, Günther Heydemann, Max Schreck, Louis Blenker

Ferdinand von Zeppelin, Günther Jauch, Nikolaus Harnoncourt, Sepp Blatter, Alfred Grosser

Herta Müller, Günter Grass, Joachim Gauck, Hans-Dietrich Genscher, Koča Popović

Max Frisch, Thomas Gottschalk, Jan Josef Liefers, Rainer Werner Fassbinder, Christa Wolf

Reinhard Lakomy, James Last, Herbert Achternbusch, Fritz Hauser, Hans-Peter Pfammatter

Karlheinz Böhm, Ricarda Huch, Michael Ballhaus, Arnold Zweig, Michael Fassbender

Ferdinand Hodler, Johan Zoffany, Hans Thoma, Arne Jacobsen, Lucas Cranach the Younger

Friedrich Wilhelm von Seydlitz, Dagobert Sigmund von Wurmser, Heinz Guderian, Ernst Gideon von Laudon, George Olivier, count of Wallis

Heinz Sielmann, Wieland Schmied, Manfred Krug, Paul Maar, Armin Mueller-Stahl

Pope Benedict XVI, Willy Brandt, Angela Merkel, Helmut Schmidt, Kurt Biedenkopf

Elizabeth Lavenza, Hans Fugger, Baron Strucker, Herbert of Wetterau, Prince Johannes of Liechtenstein

Marius Müller-Westernhagen, Karl Richter, Reinhard Lakomy, Michael Cretu, Paul van Dyk

Erika Mann, Frank Wedekind, Til Schweiger, Fritz von Opel, Carmen Electra

Gerhart M. Riegner, Viktor de Kowa, Otto Sander, Hans Hass, Dorothee Sölle

Jean-Claude Juncker, Richard von Weizsäcker, Herta Müller, Konrad Adenauer, Helmut Kohl

Herbert Prikopa, Till Lindemann, Nico, Klaus Voormann, Jakob Adlung

Stefan Hell, Franz-Ulrich Hartl, Reinhard Genzel, Charles Weissmann, Harald zur Hausen

Günter Grass, Herta Müller, Heinrich Böll, Peter Handke, Juli Zeh

Günter Grass, Peter Scholl-Latour, Elfriede Jelinek, Juli Zeh, Christa Wolf

Frank Thiess, Jessica Hausner, Elmar Wepper, Wolf Jobst Siedler, Marc Rothemund

Heinrich von Brentano, Ernst Benda, Gustav Heinemann, Heiner Geißler, Heinrich Albertz

Magneto, Nightcrawler, Sinterklaas, Silent Night, Victor Frankenstein 
Steve Jobs

Steven Spielberg

Tiger Woods

Walt Disney

John F. Kennedy

Charles Lindbergh

Rosa Parks

Serena Williams
Victor Klemperer, Joschka Fischer, Jürgen Kuczynski, Joachim Fest, Dieter Hallervorden

Herta Müller, Jean-Claude Juncker, Hans-Dietrich Genscher, Joachim Gauck, Koča Popović

Charles Dutoit, Shania Twain, Lise Meitner, Michael Haneke, Otto Hahn

Shania Twain, Charles Dutoit, Lise Meitner, Otto Hahn, Michael Haneke

Bernhard von Bülow, Otto von Habsburg, Hans-Jochen Vogel, Prince Henry of Prussia, Frederick Augustus III of Saxony

Pina Bausch, Ferdinand von Zeppelin, Nikolaus Harnoncourt, Jan Josef Liefers, Wolf Biermann

Hermann Lenz, Wilhelm Feldberg, Horst Tappert, Peter Stein, Gert Jonke

Charles Dutoit, Lise Meitner, Michael Haneke, Richard von Coudenhove-Kalergi, Klaus Clusius

Table 7: We show top-5 predictions out of the top-100 for American $\rightarrow$ German adaptations on the Veale NOC subset using WikiData. These are compared to our human annotations in our results. 

tions on the Veale NOC

Abraham Lincoln

Al Capone

Alfred Hitchcock

Benedict Arnold

Bill Gates

Britney Spears

Charles Lindbergh

Donald Trump

Elvis Presley

Ernest Hemingway

Frank Lloyd Wright

George Washington

Henry Ford

Hillary Clinton

Homer Simpson

Jack The Ripper:Ripper

Jay Z

Jimi Hendrix

John F. Kennedy

Kim Kardashian

Louis Armstrong

Marilyn Monroe

Michael Jordan

Neil Armstrong

Noam Chomsky

Oprah Winfrey

Orville Wright

Richard Nixon

Rosa Parks

Serena Williams

Steve Jobs
Napoleon, Napoléon Bonaparte, Erzherzog Johann, Otto von Bismarck, Kaiser Wilhelm II.

Nazis, SA-Mann, Verhaftungswellen, Judenverfolgung, Fluchthilfe

Fritz Lang, Helmut Käutner, Willi Forst, Emil Jannings, Heinz Rühmann

Russlandfeldzug 1812, Schlacht bei Roßbach, Jean-Victor Moreau, schwedischen Armee, Alexander Wassiljewitsch Suworow congstar, Alnatura, GMX, ChessBase, Gardeur

Glasperlenspiel, Unheilig, Helene Fischer, Christina Aguilera, Herbert Grönemeyer

Segelflieger, Flugpioniere, Zeppelins, Adolf Hitler, Caproni

Deutschland, Österreich, Trump, Strache, Bundestagswahlkampf

Udo Jürgens, Elvis Presley, Hits, den Beatles, der Beatles

Stefan Zweig, Franz Werfel, Joachim Ringelnatz, Hermann Hesse, Gottfried Benn

Adolf Loos, Le Corbusier, Bruno Schmitz, Entwürfen, Fritz Höger Napoléon Bonaparte, Friedrich dem Großen, Napoleon, Friedrich der Große, Napoleon Bonaparte

Ferdinand Porsche, Büssing, Krupp, Ettore Bugatti, Steyr-DaimlerPuch

Deutschland, Bundestagswahlkampf, Österreich, Sarkozy, Strache Eingangsszene, verulkt, Schlusssequenz, Off-Stimme, Muminfamilie

Tat, Werwolf, Täter, Dritten Reich, Mörder

Xavier Naidoo, D-Bo, Sido, Rosenstolz, David Guetta

Udo Jürgens, Tangerine Dream, Jimi Hendrix, Pink Floyd, Depeche Mode

Adolf Hitler, Bundeskanzlers, Adolf Hitlers, Adolf Hitler, Hitler

Kaas, gotv, Frank Zander, Herbert Grönemeyer, Roland Kaiser

Richard Tauber, Django Reinhardt, Udo Jürgens, Sidney Bechet, Jazzorchester

Marlene Dietrich, Lil Dagover, Elisabeth Bergner, Brigitte Bardot, Romy Schneider

Powerplay, Xavi, Predrag Mijatović, NHL-Historie, Franck Ribéry Juri Gagarin, Vorbeiflug, Weltraum, Raumstation Mir, Raumfahrer Jürgen Habermas, Hans-Ulrich Wehler, Carl Schmitt, Theodor W. Adorno, Norbert Elias

Harald Schmidt, Thomas Gottschalk, Satiresendung, ORFSendung, Hape Kerkeling

Parseval, Luft Hansa, Hugo Junkers, Ernst Heinkel, Claude Dornier

Österreich, Deutschland, Bundeskanzler, Bundeskanzlers, Bundespräsidenten

NS-Militärjustiz, Franz Jägerstätter, NS-Opfer, Bücherverbrennung, Baum-Gruppe

Dick Jaspers, Philipp Kohlschreiber, Semifinale, Achtelfinale, Dominic Thiem

Steve Jobs, Sony, Electronic Arts, Netscape, Atari 
Steven Spielberg

Superman

Tiger Woods

Walt Disney
Hörspielproduktion, Helmut Käutner, Fellini, Oliver Hirschbiegel, Kinofilm

Superman, Batman, Superhelden, Monster, Spider-Man

Rekordeuropameister, Österreich, spanische Team, ÖFBCupsieger, Deutschland

Fritz Lang, Sascha-Film, Fellini, UFA, "Das Cabinet des Dr. Caligari"

Table 8: We show top-5 predictions out of the top-100 for American $\rightarrow$ German adaptations on the Veale NOC subset using $\mathbf{3 C o s A d d}$. These are compared to our human annotations in our results. 

tions on the Veale NOC

Abraham Lincoln

Al Capone

Alfred Hitchcock

Benedict Arnold

Bill Gates

Britney Spears

Charles Lindbergh

Donald Trump

Elvis Presley

Ernest Hemingway

Frank Lloyd Wright

George Washington

Henry Ford

Hillary Clinton

Homer Simpson

Jack The Ripper:Ripper

Jay Z

Jimi Hendrix

John F. Kennedy

Kim Kardashian

Louis Armstrong

Marilyn Monroe

Michael Jordan

Neil Armstrong

Noam Chomsky

Oprah Winfrey
Konrad Adenauer, Helmut Schmidt, Willy Brandt, Helmut Kohl, Adenauer

Andreas Baader, Leo Katzenberger, Paul Schäfer, Strippel, Hermann Langbein

Helmut Käutner, Til Schweiger, Mario Adorf, Paul Verhoeven, Dennis Hopper

Otto von Bismarck, Bismarcks, Bismarck, Preußens, Kaiserreiches Martin Winterkorn, Volkswagen AG, DaimlerChrysler, Robert Bosch GmbH, Volkswagen AG

Sarah Connor, Nena, Helene Fischer, Lena Meyer-Landrut, Moses Pelham

Chaim Weizmann, Tomáš Garrigue Masaryk, Ferdinand Sauerbruch, Fritz Haber, Chaim Arlosoroff

Helmut Schmidt, Angela Merkel, Gerhard Schröder, Helmut Kohl, Bundesaußenminister

Udo Jürgens, Peter Maffay, Cliff Richard, Achim Reichel, Lou Reed

Paul Schlenther, Marcel Reich-Ranicki., Timothy Leary, Erwin Leiser, Alice Walker

Albert Einstein, Max Planck, Max Born, Hermann von Helmholtz, Arnold Sommerfeld

Otto von Bismarck, Otto von Bismarck, Konrad Adenauer, Engelbert Dollfuß, Joseph Wirth

Ernst Abbe, Carl Duisberg, Bubbe, Aby Warburg, Sybel

Angela Merkel, Angela Merkel, Helmut Schmidt, Gerhard Schröder, Bundesinnenminister

Rolf Hochhuth, Carl Bernstein, Uwe Tellkamp, Wolfgang Völz, Richard Gere

Sarah Connor, Spike Jonze, Timberlake, "Das Urteil", "Nichts als die Wahrheit"

will.i.am, Moses Pelham, Silbermond, Xavier Naidoo, Kanye West Peter Maffay, Udo Lindenberg, Depeche Mode, Xavier Naidoo, Die Toten Hosen

Konrad Adenauer, Helmut Schmidt, Willy Brandt, Helmut Kohl, Bundeskanzler

Heidi Klum, Ruth Moschner, Ellen DeGeneres, Circus HalliGalli, Oliver Pocher

Peter Maffay, Radioaufnahmen, Udo Lindenberg, Achim Reichel, Helge Schneider

Walter Giller, Jessica Tandy, Liv Ullmann, Edgar Selge, Betty White

Dirk Nowitzki, Toni Kroos, Zlatan Ibrahimović, Xavi, Zinédine Zidane

Max von Laue, Albert Einstein, Chaim Weizmann, Johannes R. Becher, Ernst Abbe

Albert Einstein, Nobelpreisträger, Max Planck, American Psychological Association, Hans Bethe

Anja Kling, "Forsthaus Falkenau", Uschi Glas, "Saturday Night Live"., Anke Engelke 
Orville Wright

Richard Nixon

Rosa Parks

Serena Williams

Steve Jobs

Steven Spielberg

Superman

Tiger Woods

Walt Disney
Kawaishi, Rjabuschinski, Monistenbund, Dethmann, Leo Baeck Instituts

Helmut Schmidt, Konrad Adenauer, Willy Brandt, Helmut Kohl, Gerhard Schröder

Sophie Scholl, Die letzten Tage, Emil Jannings., Ruth Wilson, Monica Bleibtreu

Max Schmeling, Wilfried Dietrich, Gottfried von Cramm, Henry Maske, László Kubala

DaimlerChrysler, Volkswagen, Siemens, Sanyo, Fujitsu

Til Schweiger, Ethan Hawke, Matthias Schweighöfer, Samuel L. Jackson, Ryan Reynolds

Jabberwocky, Freaks, Scarface, Leatherface, Krabat

Dirk Nowitzki, deutschen U21-Nationalmannschaft, MTV Gießen, Mats Hummels, Franz Beckenbauer

Helmut Dietl, Peter Ustinov, David Mamet, Rainer Werner Fassbinder, Sönke Wortmann

Table 9: We show top-5 predictions out of the top-100 for American $\rightarrow$ German adaptations on the Veale NOC subset with our Learned Adaptation approach. These are compared to our human annotations in our results. 